\title{
POTENCIAL DE EROSÃO DA BACIA DO RIO UBERABA
}

\author{
RENATO F. DO VALLE JÚNIOR ${ }^{1}$, JOÃO A. GALBIATTI ${ }^{2}$, \\ MARCÍLIO V. MARTINS FILHO ${ }^{3}$, TERESA C. T. PISSARRA ${ }^{4}$
}

\begin{abstract}
RESUMO: Este trabalho teve por objetivo identificar qualitativamente as áreas suscetíveis à erosão laminar na bacia do Rio Uberaba, localizada em Uberaba - MG, apoiado no modelo matemático da Equação Universal de Perda de Solo (EUPS). Foram utilizadas cartas de: solos, uso e ocupação das terras, redes de drenagem, declividade e dados pluviográficos, utilizando-se de um Sistema de Informação Geográfica (SIG - IDRISI). A espacialização do potencial de erosão só foi possível a partir da estimativa da tolerância às perdas laminares para cada tipo de solo da bacia, e da profundidade dos solos, por entender que as perdas são mais significativas em solos mais rasos do que em solos muito profundos. Na análise dos resultados, verificou-se que $37 \%$ da área total da bacia do Rio Uberaba $\left(905,24 \mathrm{~km}^{2}\right)$ sofrem perdas de solos acima do limite de tolerância, sendo $12 \%$ em solos profundos e $25 \%$ em muito profundos, e a espacialização deste evento favorece a adoção de ações efetivas quanto à conservação dos solos da bacia.
\end{abstract}

PALAVRA-CHAVE: USLE, erosão, impacto ambiental.

\section{POTENTIAL OF EROSION IN UBERABA RIVER WATERSHED}

\begin{abstract}
This work aimed to identify qualitatively the areas susceptive to laminar erosion in Uberaba river watershed, located in Uberaba-MG, Brazil, based on the mathematical model of the Universal Soil Loss Equation (USLE). The following maps had been used: soil, land use, drainage net, slope and rainfall data, using a Geographic Information System (GIS - IDRISI) to analyze and manage the data that are linked to the location. The spatiality of the potential of erosion was possible from the estimative of the tolerance to laminar losses for each kind of soil in the watershed and soil depth, to understand that the losses are more significant in flatter soil than in very deep ones. In the analysis of the results, it was verified that $37 \%$ of the total area of the watershed of the Uberaba river $\left(905,24 \mathrm{~km}^{2}\right)$ showed losses above the tolerance limit, being $12 \%$ in deep soil and $25 \%$ in very deeply ones, and the spatiality of this event, regards to effective the actions due to soil conservation of the watershed.
\end{abstract}

KEYWORDS: USLE, erosion, environmental impact.

\section{INTRODUÇÃO}

As formas de erosão que ocorrem nas bacias hidrográficas são consideradas um dos problemas mais sérios da atualidade, influenciando a produção agrícola, devido ao consequente empobrecimento do solo e ao abastecimento de água, acarretando a diminuição de sua disponibilidade nos reservatórios devido ao assoreamento.

A erosão laminar é um processo iniciado pelo impacto direto das gotas de chuva sobre o solo, que desagregam as partículas, e estas, conforme o tamanho, são facilmente transportadas pelo escoamento superficial (FARINASSO, 2005). Esse tipo de erosão ocorre de forma frequente em áreas agrícolas, durante o período de preparo do solo e plantio, onde geralmente o solo se encontra desprovido de cobertura vegetal. Desta forma, são perdidos, no Brasil, cerca de 500 milhões de

\footnotetext{
${ }^{1}$ Prof. Dr., Instituto Federal de Educação Ciência e Tecnologia do Triângulo Mineiro, Câmpus Uberaba - MG, renato@iftm.edu.br.

${ }^{2}$ Prof. Dr., Faculdade de Ciências Agrárias e Veterinárias, UNESP, Câmpus de Jaboticabal - SP, galbi@ @cav.unesp.br.

${ }^{3}$ Prof. Dr., Faculdade de Ciências Agrárias e Veterinárias, UNESP, Câmpus de Jaboticabal - SP, mfilho@ @cav.unesp.br.

${ }^{4}$ Profa. Dra., Faculdade de Ciências Agrárias e Veterinárias, UNESP, Câmpus de Jaboticabal - SP, teresap@ fcav.unesp.br.

Recebido pelo Conselho Editorial em: 3-7-2008

Aprovado pelo Conselho Editorial em: 7-8-2010
} 
toneladas de terra anualmente, correspondendo ao desgaste de $15 \mathrm{~cm}$ de espessura numa área de 280.000 hectares (BERTONI \& LOMBARDI NETO, 1999).

A erosão em sulcos ocorre principalmente pelo escoamento superficial concentrado em função das irregularidades da vertente, sendo um processo de incisão vertical mais ou menos profundo no terreno que pode ser prevenido utilizando-se de técnicas apropriadas de conservação do solo, no início do processo. Caso os sulcos não sejam rapidamente revertidos, o processo de erosão intensifica-se gerando voçorocas, que podem ser entendidas como grandes cavidades, em profundidade e em extensão, dependendo da maciez e coesão dos materiais constituintes do perfil do solo, que já atingiram o nível do lençol freático (BAPTISTA, 2003).

As atividades de exploração intensiva de recursos naturais, como a atividade agrícola, são classificadas como de alto potencial de impacto ambiental e econômico (CASTRO \& VALÉRIO FILHO, 1997). O uso inadequado do solo na bacia do alto curso do Rio Uberaba poderá gerar catástrofes ao meio ambiente, visto que, à medida que há avanço tecnológico, as áreas que deveriam ser permanentemente preservadas estão sendo destruídas lentamente (ABDALA, 2005).

Diagnósticos ambientais preliminares têm sido realizados na bacia do Rio Uberaba, junto a sua área de proteção ambiental (APA), onde se destaca a deterioração ambiental crescente, devido ao uso e ocupação inadequados dos solos (FABIAN \& TORRES, 2003).

Como o fenômeno da erosão está correlacionado à queda da produtividade agrícola, muitos trabalhos concentram-se na compreensão do fenômeno ou ainda no desenvolvimento de técnicas de recuperação do potencial produtivo em função do processo erosivo (SILVA et al., 2003). Assim, medidas de controle e de planejamento para o uso adequado das terras são necessárias, como a aplicação de modelos matemáticos, como a Equação Universal de Perda de Solo (EUPS), que prediz a perda de solo de uma determinada área em função dos fatores que representam o clima, o solo, o relevo e o uso da terra.

A Equação Universal de Perda de Solo (EUPS), quando espacializada por meio de um Sistema de Informação Geográfica (SIG), tem possibilitado a estimativa de perdas de solos em bacias hidrográficas (PRUSKI et al., 2006). Assim sendo, a aplicação da EUPS em escala municipal é válida para estudos qualitativos sobre predição de perdas de solos (FARINASSO, 2005), possibilitando a delimitação e a espacialização de áreas com maior e menor suscetibilidade à erosão, favorecendo o zoneamento ambiental e, consequentemente, o planejamento ambiental. Dentro desta ótica, o presente trabalho visa a diagnosticar qualitativamente o potencial de erosão dos solos da bacia do Rio Uberaba, através da integração dos fatores climatológicos, pedológicos, topográficos e antrópicos, obtidos mediante a utilização da equação universal de perda de solo (EUPS), identificando geograficamente áreas críticas quanto à erosão potencial.

\section{MATERIAL E MÉTODOS}

A bacia do Rio Uberaba, região sob cerrado, está situada entre os paralelos $19^{\circ} 30^{\prime} 37^{\prime \prime}$ e

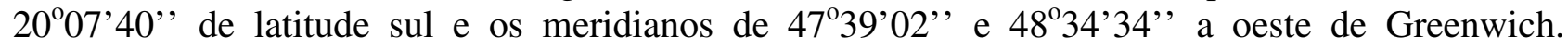
Abrange grande parte dos municípios de Uberaba, Veríssimo e Conceição das Alagoas, Campo Florido e parte de Planura, possuindo uma área aproximada de $2.419 \mathrm{~km}^{2}$, destacando-se por sua importância em termos de recursos hídricos e aspectos econômicos ligados às atividades agrícolas (Figura 1).

Para realizar as etapas com o Sistema de Informações Geográficas (SIG), utilizou-se do software IDRISI (SIG-IDRISI) para a elaboração dos planos de informação apresentados na pesquisa, onde sua metodologia operacional se encontra apresentada na Figura 2. Foi utilizada a Equação Universal de Perda de Solo (EUPS) para estimar os valores de perda de solo por unidade de área, seguindo a forma de WISCHMEIER \& SMITH, 1978:

$$
\mathrm{A}=\mathrm{R} \text { K L S C P }
$$

em que, 
A - perda de solo por unidade de área, $\mathrm{tha}^{-1}$;

$\mathrm{R}$ - erosividade da chuva, $\mathrm{MJ} \mathrm{mm} \mathrm{ha}^{-1} \mathrm{~h}^{-1}$;

$\mathrm{K}$ - erodibilidade do solo, $\mathrm{t} \mathrm{h} \mathrm{MJ}^{-1} \mathrm{~mm}^{-1}$;

L - comprimento de rampa, adimensional;

$\mathrm{S}$ - declividade de rampa, adimensional;

$\mathrm{C}$ - fator de uso e manejo do solo, adimensional, e

$\mathrm{P}$ - índice relativo à prática conservacionista adotada, adimensional.

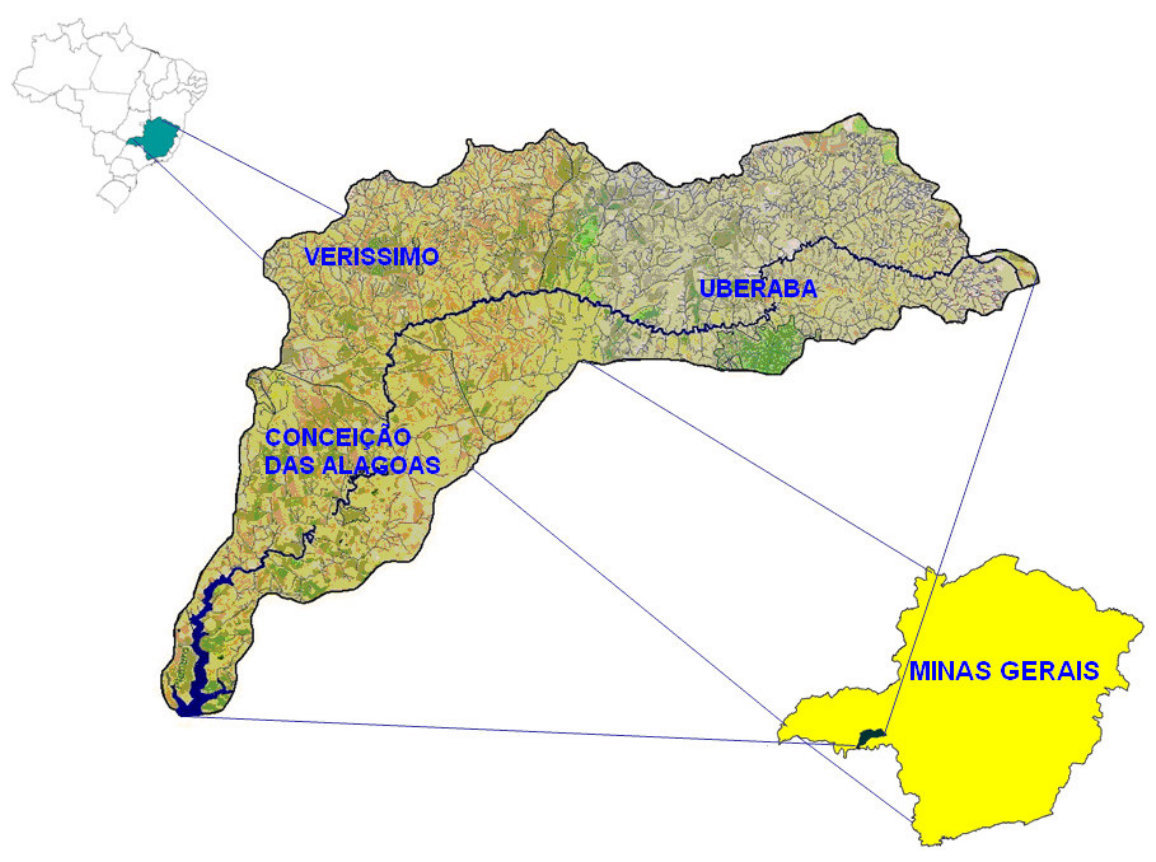

FIGURA 1. Localização da bacia do Rio Uberaba, no Triângulo Mineiro-MG. Location of the Uberaba river watershed, in the Triângulo Mineiro,MG.

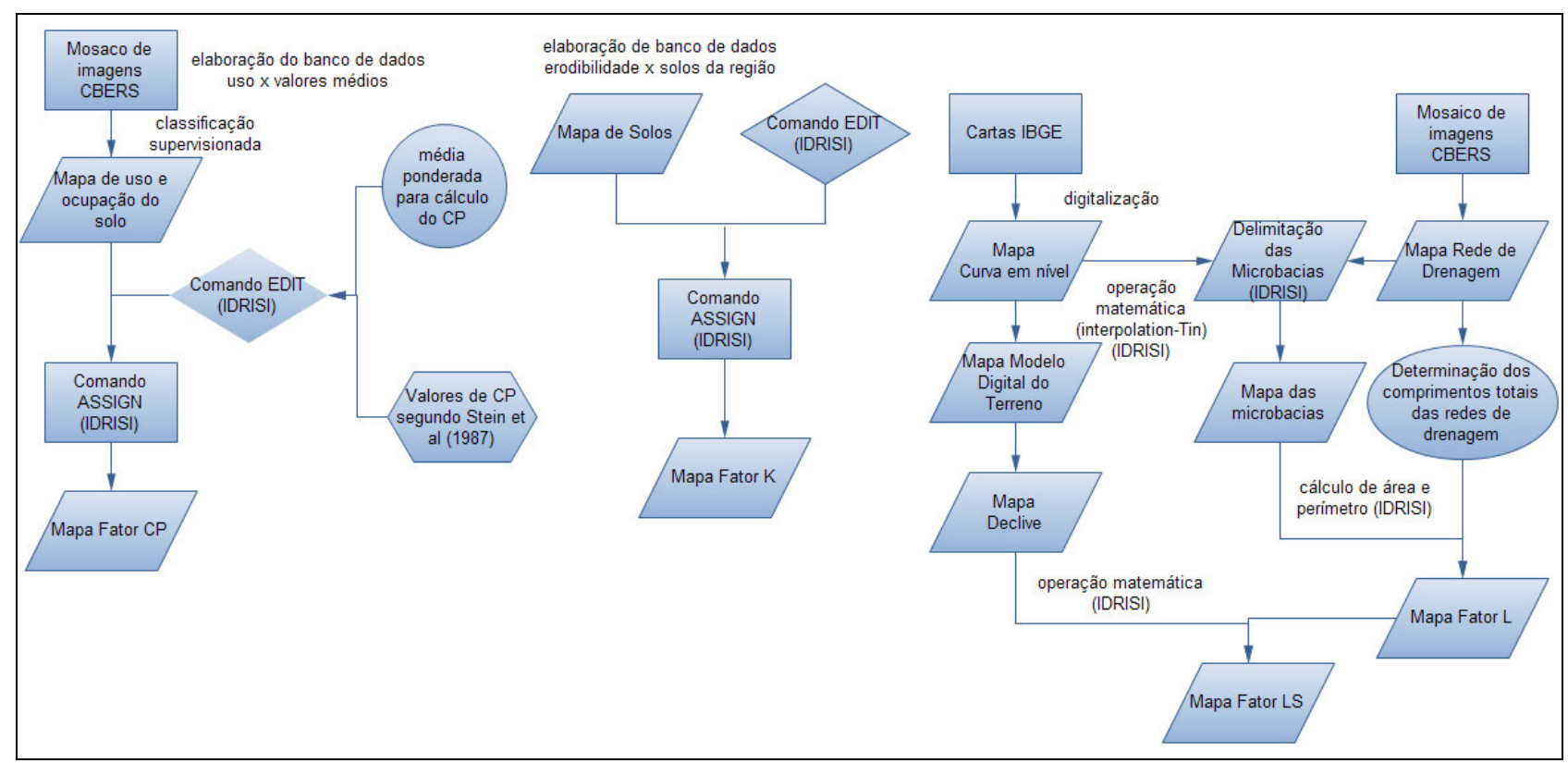

FIGURA 2. Metodologia empregada no SIG-IDRISI para a obtenção dos mapas de declive, fator (LS), (L), (CP) e (K). Methodology applied in the GIS-IDRISI for obtaining the decline maps, factor $(\mathrm{LS}),(\mathrm{L}),(\mathrm{CP})$ and $(\mathrm{K})$. 
A EUPS foi utilizada para estimar o potencial de erosão, considerando os fatores componentes dos termos da formulação do modelo apresentado. Para o cálculo do fator erosividade (R), foram utilizados registros contínuos cotados dos pluviogramas diários da cidade de Uberaba (MG), do período entre janeiro de 1999 e dezembro de 2005, obtidos junto à Estação Climatológica do INMET (Instituto Nacional de Meteorologia), onde se calcularam as energias cinéticas totais das chuvas.

Foram consideradas chuvas individuais aquelas separadas por mais de seis horas. As chuvas menores que $10 \mathrm{~mm}$, com intensidade máxima menor que $24 \mathrm{~mm} \mathrm{~h}^{-1}$ para uma duração de $15 \mathrm{~min}$, foram consideradas não erosivas.

Para o cálculo da energia cinética, foi utilizada a equação de WISCHMEIER \& SMITH (1958), ajustada ao Sistema Internacional de Unidades por FOSTER et al. (1981), dada por:

$$
\mathrm{EC}=0,119+0,0873 \log \mathrm{I}
$$

sendo,

EC - energia cinética da chuva no segmento, $\mathrm{MJ} \mathrm{ha}^{-1} \mathrm{~mm}^{-1}$, e

$\mathrm{I}$ - intensidade da chuva, $\mathrm{mm} \mathrm{h}^{-1}$.

Os resultados encontrados mediante o uso desta equação foram multiplicados pela lâmina de chuva precipitada em cada segmento e, em seguida, realizada a soma dos valores para uma mesma chuva individual.

Na obtenção do índice $\mathrm{EI}_{30}\left(\mathrm{MJ} \mathrm{mm} \mathrm{ha}{ }^{-1} \mathrm{~h}^{-1}\right.$ ), foi identificada a maior lâmina de chuva precipitada em 30 minutos no pluviograma, com a qual se calculou a intensidade máxima de chuva observada nessa duração, utilizando a eq.(3) (WISCHMEIER \& SMITH ,1958).

$$
\mathrm{EI}_{30}=\mathrm{EC} \mathrm{I}_{30}
$$

Com o valor de EI30, obtido em cada precipitação, foi possível determinar os índice de erosividade mensais e, posteriormente, os anuais, para a cidade de Uberaba.

Para a estimativa da erodibilidade do solo (fator K), a ser obtida de forma indireta, partiu-se da avaliação dos perfis de solos gerados do mapeamento (EMBRAPA/EPAMIG, 1982), realizado na área de estudo, e da coleta de 92 pontos amostrais ao longo da bacia. Em cada um, coletaram-se 20 amostras simples na profundidade de $20 \mathrm{~cm}$, gerando-se uma amostra composta para cada ponto, com base nas quais se realizaram análises físicas e químicas do solo. Calculou-se o valor médio da erodibilidade para cada tipo de solo presente na bacia, utilizando-se da metodologia indireta de DENARDIN (1990) e ROLOFF \& DENARDIN (1994).

O método desenvolvido por ROLOFF \& DENARDIN (1994) baseia-se em parâmetros físicos, tais como percentagem de silte, areia fina e permeabilidade codificada por WISCHMEIER et al., (1971) determinada mediante nomograma correlacionando características físicas e estruturais do solo, sendo definida pela eq.(4):

$$
\mathrm{K}=0,004 \mathrm{P}+\left(\mathrm{Mn}^{0,5}\right)
$$

em que,

$\mathrm{Mn}-(\%$ silte $) .((\%$ silte $)+(\%$ areia muito fina $)), \mathrm{e}$

$\mathrm{P}$ - permeabilidade codificada por WISCHMEIER et al. (1971).

Para a quantificação do fator K, adotou-se a equação de DENARDIN (1990), sendo:

$$
\mathrm{K}=0,00000748 \mathrm{M}+0,00448059 \mathrm{P}-0,06311750 \mathrm{DPM}+0,01039567 \text { X32 }
$$

em que, 
$\mathrm{M}$ - novo silte (novo silte + nova areia);

P - permeabilidade codificada, segundo WISCHMEIER et al. (1971);

DMP - diâmetro médio ponderado das partículas do solo inferiores a 2,00 mm, e $\mathrm{X} 32$ - nova areia $(\mathrm{MO} / 100)$.

Utilizou-se um simulador de chuvas, que estima de forma direta a erodibilidade dos solos, para quantificar as perdas por erosão laminar em um Latossolo Vermelho distroférrico (EMBRAPA, 1999). Parcelas experimentais, com preparo do solo e alinhamento no sentido da declividade do terreno, nos declives $(2 ; 3$ e $6 \%$ ), foram instaladas com as dimensões $0,50 \mathrm{~m}$ de largura e $0,75 \mathrm{~m}$ de comprimento $\left(0,38 \mathrm{~m}^{2}\right)$, executando-se quatro simulações para cada declive. As parcelas foram delimitadas com chapas metálicas nas laterais e na parte superior. Todas as parcelas apresentavam calhas coletoras metálicas, em seus limites inferiores, convergentes para uma saída de $0,10 \mathrm{~m}$ de diâmetro.

As parcelas foram submetidas à chuva com intensidade de $65,5 \mathrm{~mm} \mathrm{~h}^{-1}$, durante 60 minutos, produzida por um simulador de chuvas. Procederam-se às medidas de vazões dos escoamentos superficiais e das concentrações de sedimentos, realizadas no quinto minuto após o início da enxurrada e, a partir daí, a cada cinco minutos, conforme MARTINS FILHO (1999). Amostras de enxurrada foram coletadas em recipientes de vidro com capacidade de $1 \mathrm{~L}$, cronometrando-se o tempo de coleta. No laboratório, determinaram-se a concentração de sedimentos, o volume de solução e as taxas de perdas de solo. A solução foi avaliada gravimetricamente, em balança com resolução de $0,01 \mathrm{~g}$, e, em seguida, as amostras foram deixadas em repouso por $24 \mathrm{~h}$ para a deposição de sedimentos. Após o período de repouso de $24 \mathrm{~h}$, as amostras foram levadas à estufa a $105{ }^{\circ} \mathrm{C}$ até secagem completa. Após a secagem, as amostras foram pesadas, determinando-se o peso de sedimento de cada uma.

$\mathrm{O}$ valor de $\mathrm{K}$ determinado de forma direta, por ser o mais próximo do real, serviu como parâmetro de escolha da metodologia indireta a ser adotada na estimativa da erodibilidade dos solos da bacia. Após calculado o valor médio da erodibilidade para cada solo, elaborou-se um banco de dados em SIG-IDRISI para a espacialização do fator K no mapa de solos da bacia .

Entre os diferentes tipos de solos encontrados na bacia do Rio Uberaba, destacam-se os Latossolos Vermelho distroférrico, distrópico típico e Argisolo Vermelho-Amarelo (EMBRAPA, 1999).

Para a determinação do comprimento de rampa (com base no qual se calcula o fator L), empregou-se o método do retângulo equivalente, modificado por VILLELA \& MATTOS (1975) [eq.(6)], o qual possibilita o cálculo do comprimento de rampa, utilizando cartas topográficas. As redes de drenagem foram delimitadas a partir da digitalização efetuada em mosaico de imagens orbitais elaborada a partir do satélite CBERS 2, coletada junto ao INPE (Instituto Nacional de Pesquisas Espaciais), na escala de resolução de até 1:25,000, utilizando-se do softwares SIGIDRISI. A delimitação da área das microbacias hidrográficas foi realizada a partir dos divisores de águas, elaborado a partir do mapa de curvas de nível apresentadas nas cartas topográficas do IBGE, donde se efetuou o cálculo da área para as microbacias presentes na bacia do Rio Uberaba.

$$
\mathrm{L}=\frac{\mathrm{Ar}}{4 \mathrm{lc}}
$$

em que,

$\mathrm{L}$ - fator $\mathrm{L}$ - comprimento de rampa, $\mathrm{m}$;

Ar - área da bacia, $\mathrm{m}^{2}, \mathrm{e}$

lc - somatório do comprimento de todas as redes de drenagem da bacia, $\mathrm{m}$.

O plano de informação da declividade foi obtido conforme os passos apresentados na Figura 2, a partir do (Modelo digital do terreno) MDT, elaborado mediante o uso das cartas do IBGE, 
Uberaba (analógico) e Veríssimo (digital), na escala 1:100.000, com espaçamento entre curvas de nível a cada $50 \mathrm{~m}$.

Com a confecção do mapa do comprimento de rampa (Fator L), utilizando-se do módulo de cálculo "Image Calculator" do SIG-IDRISI, procedeu-se à execução da expressão matemática apresentada na eq.(7), resultando na junção dos mapas do comprimento de rampa e declive, gerando o fator topográfico (LS).

$$
\mathrm{LS}=0,00984 \mathrm{~L}^{0,63} \mathrm{~S}^{1,18}
$$

em que,

$\mathrm{L}$ - comprimento de rampa, m, e

$\mathrm{S}$ - declividade, $\%$.

Para a aquisição dos fatores de uso e práticas conservacionistas (Fatores C e P), buscando-se agrupar em classe os usos e ocupações do solo, obteve-se o mapa de uso e ocupação do solo da bacia, gerado a partir da classificação de imagem supervisionada da imagem CBERS, CCD bandas 3,4,2, formato Tiff, Datum WGS 84, Zona 22 , utilizando-se do SIG-IDRISI .

A partir da determinação dos valores de CP para cada uso e ocupação do solo para a pior situação quanto às praticas conservacionistas, baseado nos valores propostos por STEIN et al., (1987), citado por (BAPTISTA, 2003), foi realizada a atribuição dos mesmos às classes do mapa de uso e ocupação do solo da bacia, adotando-se um valor médio ponderado [eq.(8)] de diversos valores de CP para classes de uso do solo (atividades) e sua correspondente área de abrangência no município. O mapa do fator CP foi gerado no SIG-IDRISI, por meio do módulo “ ASSIGN” (Figura 2).

$$
\mathrm{CP} \text { médio }=\frac{\sum(\mathrm{CP} \mathrm{A})}{\mathrm{AT}}
$$

em que:

$\sum$ (CP A) - valor de CP para as diversas classes de uso do solo (atividades) multiplicada pela respectiva percentagem de área ocupada no município (\%), e

A - área total das classes de uso do solo no município.

A estimativa das perdas de solos da bacia do Rio Uberaba, baseada nos componentes calculados da EUPS, foi obtida por meio do cruzamento de todos os planos de informações, utilizando-se do módulo "Image Calculator" do SIG-IDRISI, de todos os mapas (R, K, LS e CP).

A tolerância de perdas de solo por erosão (T) foi determinada conforme o proposto por OLIVEIRA (2004), em que a partir do mapa de solos e potencial de erosão, reclassificou-se no SIGIDRISI as perdas de solos, gerando-se um mapa com três classes distintas: perdas nulas ou incipientes, perdas dentro do limite de tolerância e perdas acima do limite de tolerância (Figura 3).

Para a elaboração de um diagnóstico ambiental de perda de solos (zoneamento ambiental, determinado pelas perdas de solos), é necessária a utilização do método de classificação cruzada de dois planos de informação, utilizando-se do SIG-IDRISI, realizado entre os "mapas de perda de solos por limite de tolerância" e o "mapa de solos por profundidade" (Figura 4). 


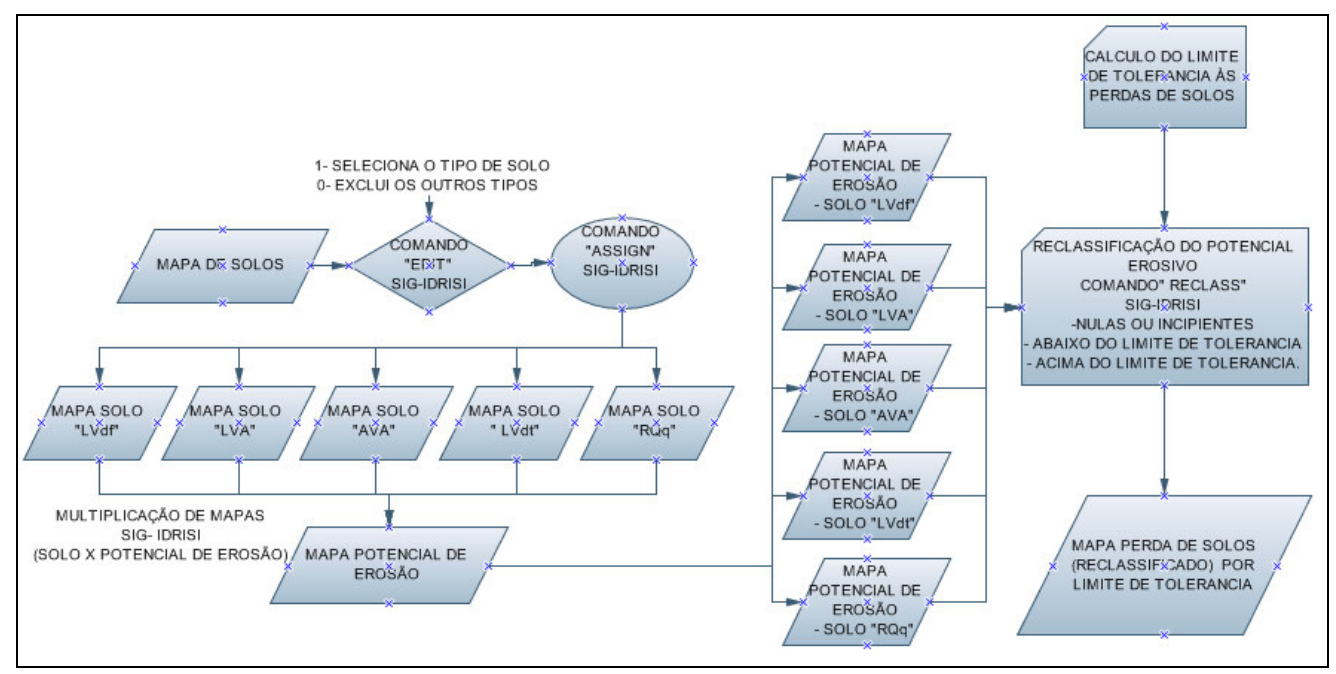

FIGURA 3. Metodologia utilizada no SIG-IDRISI para a elaboração do mapa de perdas de solo por limite de tolerância Methodology used in the SIG-IDRISI for elaboration of the soil losses map for tolerance limit.

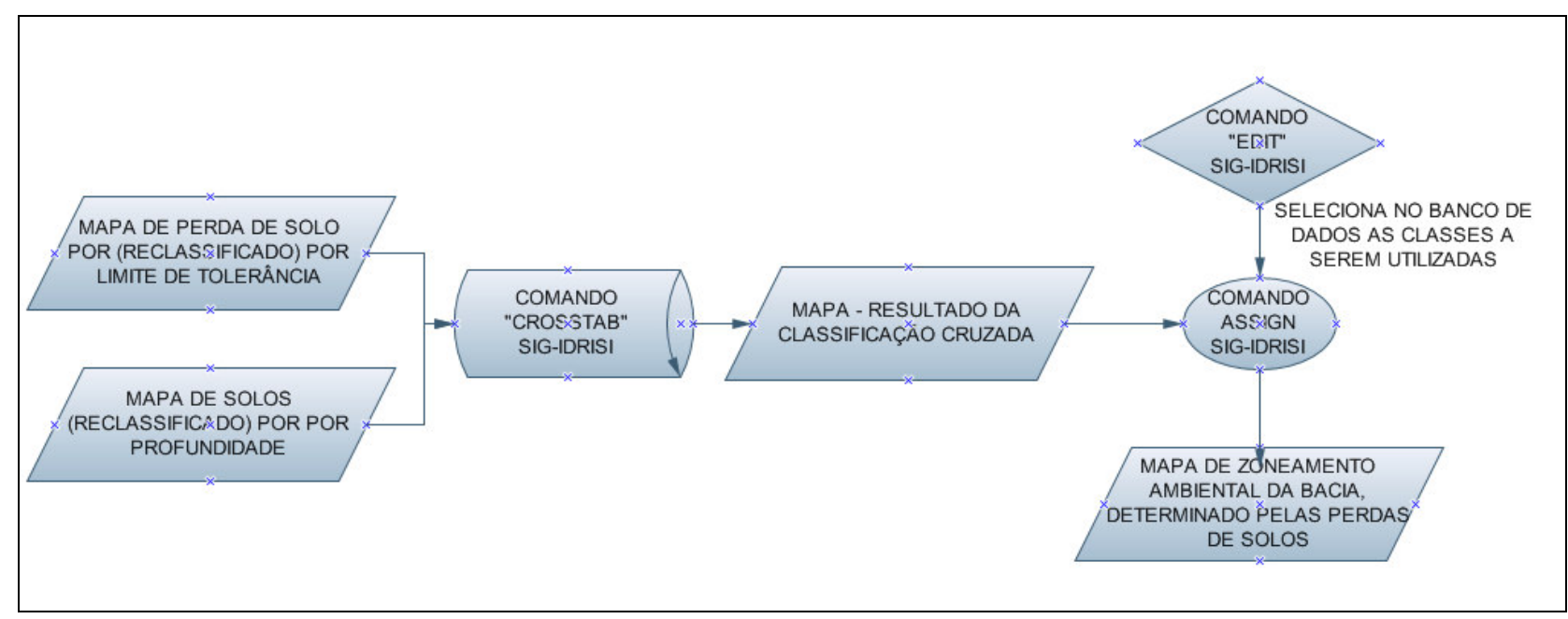

FIGURA 4. Metodologia utilizada no SIG-IDRISI para a elaboração do zoneamento ambiental determinado pelas perdas de solo. Methodology used in the SIG-IDRISI for elaboration of the environmental zoning determined by the soil losses.

\section{RESULTADOS E DISCUSSÃO}

Para a bacia do Rio Uberaba, adotou-se a erodibilidade calculada pelo método de DENARDIN (1990), por seu valor estar mais próximo dos resultados estimados mediante uso do simulador de chuvas. Os menos erodíveis são os Latossolos, que são solos maduros e profundos, isto é, mais intemperizados e profundos. À medida que o grau de maturidade e profundidade vai diminuindo, o grau de erodibilidade vai aumentando. Dessa forma, na sequência, aparecem o Argissolo e os Neossolos (Tabela 1). Os valores recomendados por BAPTISTA (2003), a partir do diagnóstico da erosão laminar no Distrito Federal, sob solo de cerrado, apresentaram-se próximos aos encontrados neste trabalho. 
TABELA 1. Erodibilidade dos solos entre métodos indiretos de determinação de $\mathrm{K}$ e simulador de chuvas. Erodibility of the soils among indirect methods of $\mathbf{K}$ determination and rain simulator.

\begin{tabular}{lcccc}
\hline \multirow{2}{*}{\multicolumn{1}{c}{ Solo }} & \multicolumn{3}{c}{ Erodibilidade - valores de K em th M J'-1 $\mathrm{mm}^{-1}$} \\
\cline { 2 - 5 } & $\begin{array}{c}\text { ROLOFF \& } \\
\text { DENARDIN } \\
(1994)\end{array}$ & $\begin{array}{c}\text { DENARDIN } \\
(1990)\end{array}$ & $\begin{array}{c}\text { BAPTISTA } \\
(2003)\end{array}$ & $\begin{array}{c}\text { Simulador de chuva } \\
\text { (área em estudo) }\end{array}$ \\
\hline Latossolo Vermelho distroférr. & 0,0150 & 0,0220 & 0,0130 & 0,0266 \\
Latossolo Vermelho distrófico & 0,0250 & 0,0170 & ---- & ---- \\
Latossolo Vermelho-Amarelo & 0,0200 & 0,0200 & 0,0200 & ---- \\
Argissolo Vermelho-Amarelo & 0,0330 & 0,0280 & 0,0300 & ----- \\
Neossolos Quartzarênicos & 0,0370 & 0,0270 & 0,0270 & ---- \\
\hline
\end{tabular}

A erodibilidade dos Latossolos brasileiros é, no mínimo, de 0,002, média de 0,011 e máximo de $0,034 \mathrm{t} \mathrm{h} \mathrm{M} \mathrm{J}^{-1} \mathrm{~mm}^{-1}$ (TOMAZONI \& GUIMARÃES, 2005), comprovando que a erodibilidade estimada pelo método de DENARDIN (1990) e adotada neste trabalho enquadra-se neste intervalo (Tabela 1).

Utilizando-se de pluviogramas de 703 chuvas, para a cidade de Uberaba, das quais 311 foram consideradas erosivas, representando $44,23 \%$ das chuvas ocorridas no período de janeiro/1999 a dezembro/2005, calculou-se a erosividade, baseando-se nas equações 2 e 3 para a região, sendo o total anual de 7.846,54 MJ mm ha ${ }^{-1} \mathrm{~h}^{-1}$ ano $^{-1}$ e desvio-padrão de 2.124,16 MJ mm ha ${ }^{-1} \mathrm{~h}^{-1}$ ano $^{-1}$, sendo classificada como erosividade forte, segundo SILVA et al. (2003).

Os comprimentos de rampa de $0,2 \mathrm{~km}$ e $0,4 \mathrm{~km}$ correspondem a $73,75 \%$ do total das microbacias avaliadas na bacia do Rio Uberaba. Portanto, embora a bacia não tenha um relevo acentuado, o fator LS exerce influência importante no processo erosivo, mas não sendo o principal agente causador da erosão na bacia. O grau de declive e o comprimento da encosta influenciam na velocidade de escoamento superficial, favorecendo a erosão em termos de tamanho e quantidade de material transportado (SILVA et al,, 2003). Os valores do fator CP foram obtidos de um valor médio ponderado, norteado pelo uso e ocupação do solo, conforme apresentado na Tabela 2. Na bacia, predominam formas de uso que protegem pouco o solo, como lavouras e pastagens, cujos valores do Fator CP são, respectivamente, 0,163 e 0,055. Essa classe de uso e ocupação, que expõe mais o solo à erosão, abrange $38,37 \%$ da área da bacia.

TABELA 2. Valores de CP para as diversas classes de uso do solo (atividades). Values of CP for several classes of soil use (activities).

\begin{tabular}{lc}
\hline \multicolumn{1}{c}{ Uso } & CP (adimensional) \\
\hline 1 - Lagos / Lagoas / Reservatórios & 0,00000 \\
2 - Agricultura & 0,16370 \\
3 - Pastagem & 0,05500 \\
4 - Vegetação nativa(Cerrado/Cerradão/Campo) & 0,00522 \\
5 - Reflorestamento (eucalipto, pínus) & 0,00010 \\
6 - Solo nu & 1,00000 \\
\hline
\end{tabular}

A partir da descrição dos perfis de solos presentes na bacia do Rio Uberaba, apresentado em EMBRAPA/EPAMIG (1982), calculou-se a tolerância à perda de cada solo da bacia, segundo OLIVEIRA (2004) (Tabela 3). 
TABELA 3. Valores de tolerância de perdas para os solos da bacia do Rio Uberaba. Values of tolerance of losses for soils of the Uberaba river watershed.

\begin{tabular}{lcc}
\hline \multicolumn{1}{c}{ Solos } & $\begin{array}{c}\text { Tolerância Calculada } \\
\left(\mathrm{t} \mathrm{ha}^{-1} \mathrm{ano}^{-1}\right)\end{array}$ & $\begin{array}{c}\text { Classe de Profundidade } \\
\text { EMBRAPA (1999) }\end{array}$ \\
\hline Latossolo Vermelho distroférrico (LVdf) & 22,98 & Muito profundo \\
Latossolo Vermelho-Amarelo (LVA) & 25,87 & Muito profundo \\
Argissolo Vermelho-Amarelo (PVA) & 17,78 & Muito profundo \\
Latossolo Vermelho distrófico típico (LVdt) & 14,21 & Profundo \\
Neossolos Quartzarênicos (RQg) & 2,14 & Muito profundo \\
\hline
\end{tabular}

Analisando a Tabela 3, que traz um cruzamento entre os tipos de solos, tolerância à perda de solos $\left(\mathrm{t} \mathrm{ha}^{-1} \mathrm{ano}^{-1}\right)$, vê-se que, dentre os Latossolos, os mais profundos e que suportam maiores remoções por erosão laminar, como o LVdf e o LVA (perdas toleráveis de 22,98 a 25,87 t ha ${ }^{-1}$ ano), abrangem, respectivamente, $61,31 \%$ e $4,30 \%$ da área da bacia. Nos solos mais erodíveis, como o ROg e o LVdt (perdas toleráveis de 2,14 a 14,21 t ha ${ }^{-1}$ ano ), que suportam menores remoções, são, respectivamente, $0,33 \%$ e $24,66 \%$ das áreas que ocupam. A relação existente entre tolerância à perda de solos e a profundidade dos solos foi comprovada por TOMAZONI \& GUIMARÃES (2005) e BAPTISTA (2003), segundo os quais, para as mesmas classes de solos, os valores de tolerância apresentaram-se próximos aos encontrados neste trabalho.

SILVA et al. (2003) classificam as perdas de solo como sendo: (1) $<10 \mathrm{t} \mathrm{ha}^{-1} \mathrm{ano}^{-1}$ : nula a pequena; (2) 10-15: moderada; (3) 15-50: média; (4) 50-120: média forte; (5) 120-200: forte. Na Figura 5, verifica-se a ocorrência predominante das classes 1 a 3, onde a classe 1 ocupa 42,15\% da área da bacia, a classe $2,10,62 \%$, a classe $3,34,68$, a classe $4,10,55 \%$ e a classe $5,2,00 \%$. Por sua vez, as perdas superiores a $50 \mathrm{t} \mathrm{ha}^{-1} \mathrm{ano}^{-1}$ ocorreram em locais onde houve combinação entre um relevo acidentado com solos altamente erodíveis (12,55\%). Observa-se que a distribuição espacial de suscetibilidade à erosão está associada ao relevo da região. As classes de suscetibilidade acima de $50 \mathrm{t} \mathrm{ha}^{-1}$ ano $^{-1}$ localizam-se justamente nas regiões com declive mais acentuado, pois a elevação dos declives favorece a suscetibilidade à erosão (BAPTISTA, 2003; FARINASSO, 2005).

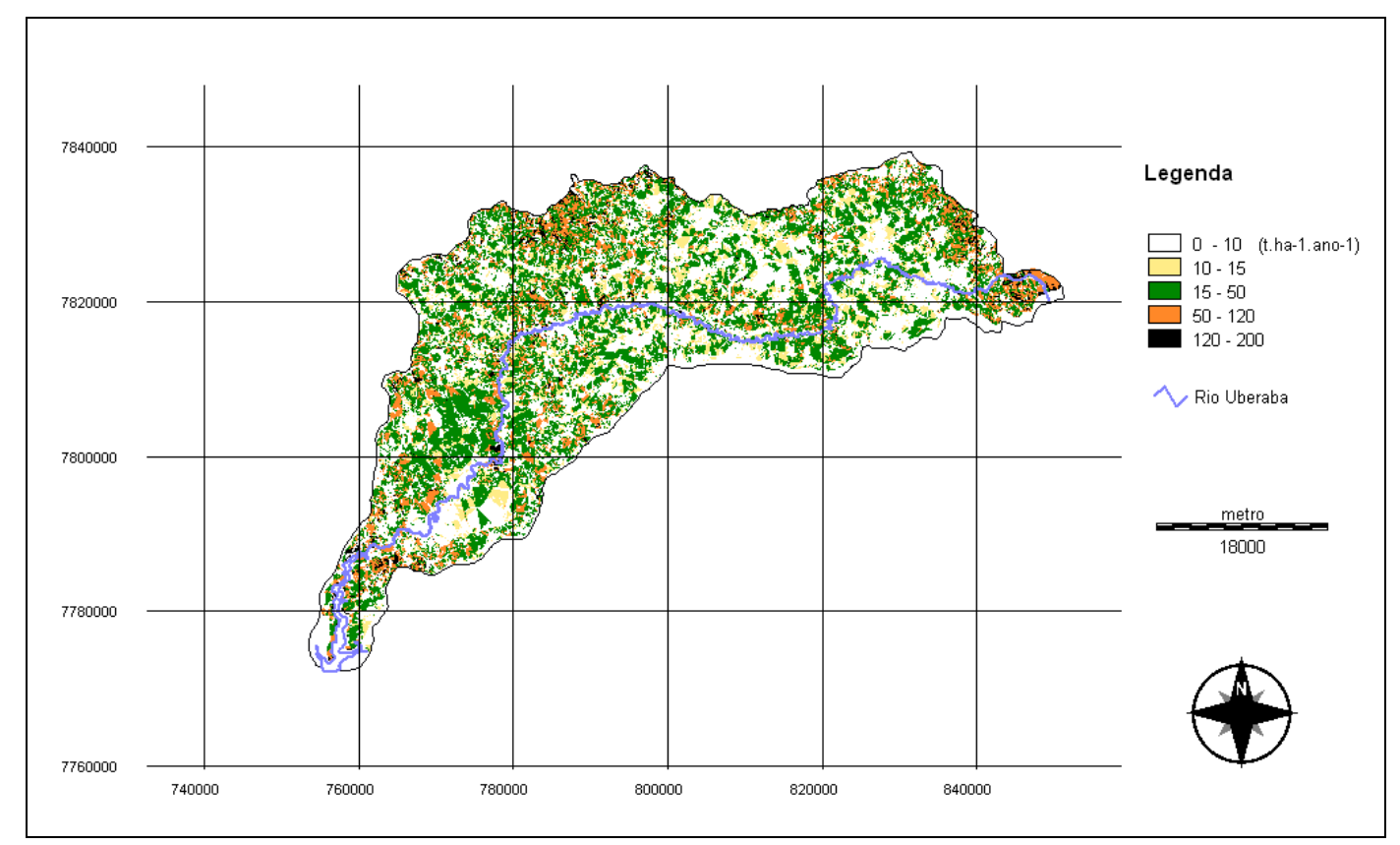

FIGURA 5. Mapa de perdas de solo da bacia $\left(\mathrm{t} \mathrm{ha}^{-1} \mathrm{ano}^{-1}\right)$. Map of soil losses of the watershed. $\left(\mathrm{t} \mathrm{ha}^{-1}\right.$ year $\left.^{-1}\right)$. 
Na confecção do mapa de zoneamento ambiental da bacia do Rio Uberaba, determinado pelas perdas de solo, as classes geradas na classificação por tabulação cruzada entre o mapa de perdas de solo por limite de tolerância ( 1 - nula e incipiente; 2 - abaixo do limite de tolerância; 3 - acima do limite de tolerância) e profundidade do solo (1 - profundo; 2 - muito profundo), geraram seis classes distintas (Tabela 4). Para melhor interpretação dos resultados, elaborou-se uma nova legenda seguindo os critérios apresentados na Tabela 5.

TABELA 4. Classes obtidas por classificação por tabulação cruzada entre profundidade do solo $\mathrm{x}$ mapa de perdas de solo por limite de tolerância. Classes obtained by classification by crossed tabulation between depth of the soil $\mathrm{x}$ map of soil losses for tolerance limit.

\begin{tabular}{ccc}
\hline Classes: Profund. & Tolerância & Observação \\
\hline 1: 1 & 1 & -- \\
$2: 1$ & 2 & \\
3: 1 & 2 & perda dentro do limite de tolerância para solo profundo \\
4: 2 & 2 & perda dentro do limite de tolerância para solo muito profundo. \\
$5: 1$ & 3 & perda acima do limite de tolerância para solo profundo. \\
6: 3 & 2 & perda acima do limite de tolerância para solo muito profundo. \\
\hline
\end{tabular}

TABELA 5. Nova legenda a ser adotada no mapa de zoneamento ambiental da bacia do Rio Uberaba, determinado pelas perdas de solo. New legend to be adopted in the map of environmental zoning of the Uberaba river watershed, determined by soil losses.

\begin{tabular}{cl}
\hline $\begin{array}{c}\text { Classes da Tabulação } \\
\text { (Tabela 4 ) }\end{array}$ & \multicolumn{1}{c}{ Novas Classes para fim de Reclassificação } \\
\hline 1 e 2 & 1 - perda nula ou incipiente \\
3 & 2 - perdas dentro do limite de tolerância em solos profundos \\
4 & 3 - perdas dentro do limite de tolerância em solos muito profundos \\
5 & 4 - perdas acima do limite de tolerância em solos profundos \\
6 & 5 - perdas acima do limite de tolerância em solos muito profundos \\
\hline
\end{tabular}

Segundo CRUZ (2002), 19,7 $\mathrm{km}^{2}$ da bacia do Rio Uberaba enquadram-se como áreas potenciais de suscetibilidade à erosão, considerando os fatores: declividade ( $>20 \%)$, solos arenosos (Argissolos), uso e ocupação do solo (pastagens e áreas agrícolas), devendo ser prioritariamente preservadas. Tais resultados, devido à não observância de outros tipos de solos, declives e parâmetros físicos, não coincidiram com os valores estimados neste trabalho, revertendo desta forma na subestimação das áreas prioritárias a serem conservadas.

Analisando o mapa de perdas de solo por limite de tolerância na bacia do Rio Uberaba, aliado à profundidade dos solos (zoneamento ambiental determinado pelas perdas de solos) (Figura 6), observa-se que as perdas por erosão laminar acima do limite de tolerância ocorrem em $25 \%$ da área da bacia para solos muito profundos $\left(611 \mathrm{~km}^{2}\right)$ e $12 \%$ para solos profundos $\left(294 \mathrm{~km}^{2}\right)$. Desta forma, as áreas prioritárias a serem preservadas não ocorrem somente em declives superiores a 20\%, mas, sim, em todos os declives e tipos de solos. A partir do zoneamento realizado, é possível estabelecer estratégias de manejo na bacia, visando à conservação do solo e água. 

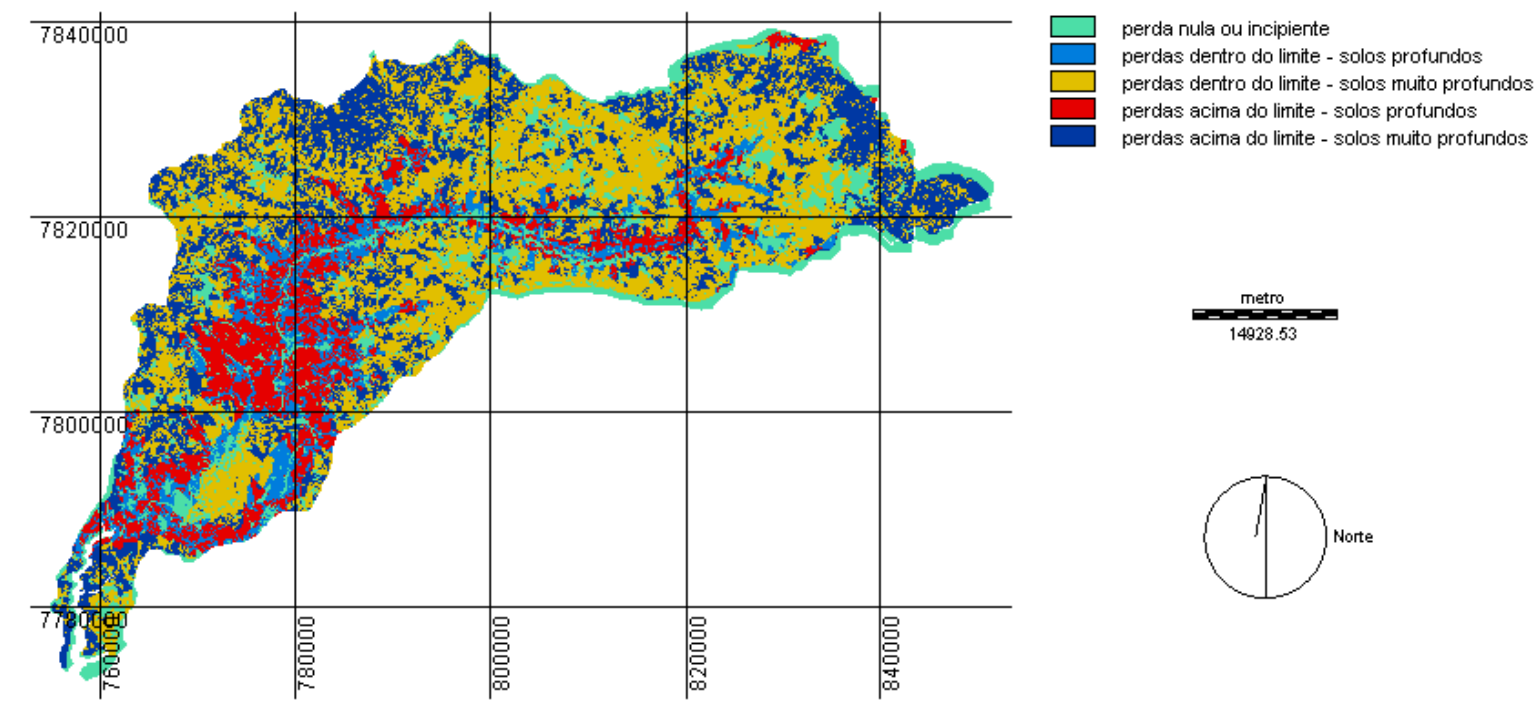

FIGURA 6. Zoneamento ambiental da bacia do Rio Uberaba, determinado pelas perdas de solo. Environmental zoning of the Uberaba river watershed, determined by the soil losses.

\section{CONCLUSÕES}

O uso da Equação Universal de perdas de solo possibilitou a estimativa qualitativa do potencial de erosão ocasionado por erosão laminar na bacia do Rio Uberaba, predominando perdas incipientes e dentro do limite de tolerância, totalizando $63 \%$ da área da bacia.

A bacia do Rio Uberaba apresenta perdas de solos acima do limite de tolerância em $37 \%$ do total de sua área, sendo $12 \%$ em solos profundos e $25 \%$ em muito profundos.

\section{REFERÊNCIAS}

ABDALA,V.L. Zoneamento ambiental da bacia do alto curso do Rio Uberaba - MG, como subsídio para gestão do recurso hídrico superficial. 200587 f. Dissertação (Mestrado em Geografia) - Universidade Federal de Uberlândia, Uberlândia, 2005.

BAPTISTA,G.M.M. Diagnóstico ambiental de erosão laminar: modelo geotecnológico e aplicação. Brasília: Universa, 2003. 140 p.

BERTONI, J.; LOMBARDI NETO, F. Conservação do solo. 4 ed. Campinas: Ícone, 1999. 355 p.

CASTRO, A.G.; VALÉRIO FILHO, M. Simulação da expectativa de perdas de solo em microbacia sob diferentes manejos florestais. Revista Brasileira de Ciência do Solo, Viçosa-MG, v.21, n.1, p.419-426, 1997.

CRUZ, L.B.S. Diagnóstico ambiental da bacia hidrográfica do Rio Uberaba-MG. 2002. 182 f. Tese (Doutorado em Engenharia Agrícola) - Universidade Estadual de Campinas, Faculdade de Engenharia Agrícola, Campinas, 2002.

DENARDIN, J.E. Erodibilidade do solo estimada por meio de parâmetros físicos e químicos. 1990. 113 f. Tese (Doutorado em Solos e Nutrição de Plantas) - Escola Superior de Agricultura "Luiz de Queiroz”, Universidade de São Paulo, Piracicaba, 1990.

EMBRAPA. EMPRESA BRASILEIRA DE PESQUISA AGROPECUÁRIA. Centro Nacional de Pesquisa de Solos. Sistema brasileiro de classificação de solos. Rio de Janeiro, 1999. 412 p. 
EMBRAPA/EPAMIG - Serviço Nacional de Levantamento e Conservação do Solo. Levantamento de reconhecimento de média intensidade dos solos e avaliação da aptidão agrícola das terras do triângulo mineiro. Rio de Janeiro. 1982. 526 p. (Boletim de Pesquisa 1 e 2 mapas)

FABIAN, A.J.; TORRES, J.L.R. Caracterização da paisagem para planejamento conservacionista em microbacia hidrográfica de Uberaba-MG. In: CONGRESSO BRASILEIRO DA CIÊNCIA DO SOLO, 29., 2003, Ribeirão Preto . Anais... Ribeirão Preto, 2003. p.35-36.

FARINASSO, M. Avaliação qualitativa do potencial erosivo em grandes áreas por meio da EUPSEquação universal de perdas de solos utilizando novas metodologias de SIG para os cálculos dos seus fatores na região do Alto Parnaíba - PI. 2005.105 f. Dissertação (Mestrado em Geografia) Universidade de Brasília, Instituto de Ciências Humanas, Brasília, 2005.

FOSTER, G.R.; McCOOL, D.K.; RENARD, K.G.; MOLDENHAUER, WC. Conversion of the universal soil loss equation to SI metric units. Journal of Soil and Water Conservation, Ankeny, v.36, p.355-359, 1981.

MARTINS FILHO, M.V. Modelagem do processo de erosão entressulcos em latossolos deJaboticabal - SP. 1999. 140 f. Tese (Doutorado em Solos e Nutrição de Plantas) - Universidade Federal de Lavras, Lavras, 1999.

OLIVEIRA, F.P. de. Determinação da tolerância de perdas por erosão para as principais ordens de solos do Estado da Paraíba. 2004. 92 f. Monografia (Trabalho de Graduação em Engenharia Agronômica) - Centro de Ciências Agrárias, Universidade Federal da Paraíba, Areia, 2004.

PRUSKI, F.F.; AMORIM, R.S.S.; SILVA, D.D.; GRIEBELER, N.P.; SILVA, J.M.A. Conservação de solo e água: praticas mecânicas para o controle da erosão hídrica. Viçosa: Universidade Federal de Viçosa, 2006. 240 p.

ROLOFF, G.P.; DENARDIN, J.E. Estimativa simplificada da erodibilidade do solo. In: REUNIÃO BRASILEIRA DE MANEJO E CONSERVAÇÃO DO SOLO E DA ÁGUA. 10., 1994, Florianópolis. Anais... Sociedade Brasileira de Ciência do Solo, 1994. p.146-147.

SILVA, A.M.; SCHULZ, H.E; CAMARGO, P.B. Erosão e hidrossedimentologia em bacias hidrográficas. São Carlos: Rima, 2003. 138 p.

STEIN, D.P.; DONZELLI, P.L.; GIMENEZ, A.F.; PONÇANO, W.L.; LOMBARDI NETO, F. Potencial de erosão laminar, natural e antrópico, na bacia do Peixe - Paranapanema. In: SIMPÓSIO NACIONAL DE CONTROLE DE EROSÃO, 3., 1987, Marília. Anais... ABGE/DAEE, 1987. v.1, p.105-135.

TOMAZONI, J.C.; GUIMARÃES, E. A sistematização dos fatores da EUPS em SIG para quantificação da erosão laminar na bacia do Rio Jirau. Revista Brasileira de Cartografia, v.57, n.3, 2005. Disponível em: <http://www.rbc.ufrj.br/2005/57_3_07.htm>. Acesso em: 5 maio 2008.

VILELA, S.M.; MATTOS, A. Hidrologia aplicada. São Paulo: McGraw Hill do Brasil, 1975.

WISCHMEIER, W.H.E.; SMITH, D.D. Predicting rainfall erosion losses: a guide to conservation planning. Washington: USDA, 1978. 58 p. (Agriculture Handbook, 537).

WISCHMEIER, W.H.; JOHNSON, C.B.; CROSS, B.V. A soil erodibility nomograph for farmland and constrution sites. Journal of Soil and Water Conservation, Ankeny, v.26, 189-193, 1971.

WISCHMEIER, W.H.; SMITH, D.D. Rainfall energy and its relationships to soil loss. Transactions of the American Geophysical Union, Washington, v.39, n.2, p.285-291, 1958. 